\title{
Bond Strength between Luting Materials and a Fiber-reinforced Resin Composite for Indirect Restorations
}

\author{
Yohsuke TAIRA, Miyuki SAKAI, Lei YANG, Takashi SAWASE and Mitsuru ATSUTA \\ Division of Applied Prosthodontics, Graduate School of Biomedical Sciences, Nagasaki University, Nagasaki, Japan \\ Corresponding author, Yohsuke TAIRA; E-mail: yohsuke@nagasaki-u.ac.jp
}

Received December 20, 2006/Accepted April 4, 2007

The purpose of the present study was to evaluate the bond strength between a fiber-reinforced composite (FRC) and six luting agents (Panavia F 2.0, Linkmax MC, Chemiace II, Multibond, Super-Bond C\&B, and Fuji I). A prosthodontic resin composite material (RC-control) and a luting agent containing no functional monomer (MT) were used as controls. Shear bond strengths between alumina-blasted FRC and the luting agents were determined after 20,000 thermocycles. The FRC showed superior bond strength when compared with the RC-control. Highest bond strengths were achieved when FRC was bonded with Panavia F 2.0, Linkmax MC, Multibond, Super-Bond C\&B, and MT, whereas Chemiace II trailed in the list of resin-based luting agents evaluated. Insufficient bonding was obtained with Fuji I. Results of the present study revealed that when fabricating restorations, the clinician should select an appropriate combination of resin composite material and luting agent so as to ensure the longevity of restorations.

Keywords: Adhesion, Cement, Glass fiber

\section{INTRODUCTION}

Light-polymerized indirect resin composites are one useful option for patients who desire esthetic dental treatment. However, clinicians occasionally encounter problems and difficulties when working with resin composite restorations, such as detachment, fracture, and wear. In the severe oral environment, proper bonding between a composite restoration and the luting material is thus of paramount importance to ensure long-term use of the restoration ${ }^{1,2)}$.

Fiber-reinforced resin composites have been studied in the context of fabricating laminate veneers $^{3,4)}$, onlays ${ }^{5)}$, crowns $^{6,7)}$, denture bases ${ }^{8,9}$, fixed partial dentures ${ }^{10-13}$, and root canal posts ${ }^{14)}$. They were characterized by flexibility and fracture resistance ${ }^{15,16)}$. The fiber materials used were glass, quartz, carbon, or polyethylene ${ }^{17-20)}$. In particular, pre-impregnated fiber-reinforced resin composites showed better physical properties and easier handling than manually mixed fiber-reinforced resin composites $^{21,22)}$. Further, for some preimpregnated fiber-reinforced resin composites employing short glass fibers with high elastic modulus, tensile strength, toughness, and impact resistance have been improved ${ }^{23,24)}$. Against this background, these materials are expected to be useful in constructing resin-bonded fixed partial dentures as well as resin composite crowns ${ }^{25-27)}$.

The bonding properties of a fiber-reinforced resin composite were evaluated based on bond strength after thermocycling ${ }^{28}$. The bond strengths of resin luting agents to fiber-reinforced composite posts were higher than those to zirconium oxide posts ${ }^{29)}$, and were significantly affected by luting agent ${ }^{29,30}$. It was found that the interfacial bonding between an experimental fiber-reinforced resin composite (FRC) containing milled glass fiber and a light-curing resin composite was strong enough to prevent delamination ${ }^{25}$. It was also reported that the FRC improved the toughness and impact resistance of the indirect resin composite. However, no information is available concerning the adhesive bonding between luting materials and this FRC material.

The purpose of the present study was to evaluate the bond strength between the FRC and six luting materials, and then compare the FRC to a conventional resin composite. When compared to conventional resin composites, the FRC is characterized by its higher rate of methacrylate monomers in addition to the unique mechanical properties mentioned above. Therefore, the tested hypothesis was that the luting materials bond to the FRC more strongly than to the conventional resin composite.

\section{MATERIALS AND METHODS}

\section{Materials}

The materials used in the present study are summarized in Table 1. FRC ${ }^{25)}$ (Sun Medical Co. Ltd., Moriyama, Japan) and a microfilled resin composite (RC-control; New Metacolor Infis Paste A3-B, Sun Medical Co. Ltd.) were used as the substrate materials. Seven luting agents were used: Panavia F 2.0 (PF; Kuraray Medical Inc., Tokyo, Japan), Linkmax MC (LM; GC Corp., Tokyo, Japan), Chemiace II (CA; Sun Medical Co. Ltd.), Multibond (MB; Tokuyama Dental Corp., Tokyo, Japan), Super-Bond C\&B (SB; Sun Medical Co. Ltd.), an experimental resin luting agent (MT), and Fuji I (FI; 
Table 1 Materials used in the present study

\begin{tabular}{|c|c|c|c|c|c|}
\hline $\begin{array}{l}\text { Material } \\
\text { (Abbreviation) }\end{array}$ & \multicolumn{2}{|l|}{ Component (\%) } & Manufacturer & $\begin{array}{l}\text { Irradiation time } \\
\text { (seconds) }\end{array}$ & Lot No. \\
\hline \multicolumn{6}{|l|}{ Substrate materials: } \\
\hline Fiber-reinforced composite & UDP AC & 41.73 & Sun Medical Co. Ltd. & 90 & 041027 \\
\hline \multirow[t]{6}{*}{$(\mathrm{FRC})$} & TEGDMA & 27.82 & Moriyama, Japan & & 040803 \\
\hline & Silanized milled-glass fiber & 24.84 & & & \\
\hline & Colloidal silica & 4.97 & & & \\
\hline & Camphorquinone & 0.30 & & & \\
\hline & Dimethyl aminobenzoic acid $2-n$-butoxy ethyl & 0.30 & & & \\
\hline & Hydroquinone monomethylether & 0.04 & & & \\
\hline New Metacolor Infis & UDMA & & Sun Medical Co. Ltd. & 90 & LS1 \\
\hline \multirow[t]{5}{*}{ Paste A3-B (R C-control) } & TEGDMA & & & & \\
\hline & Reactive prepolymerized filler & $42^{*}$ & & & \\
\hline & Dimethyl aminobenzoic acid 2 - $n$-butoxy ethyl & & & & \\
\hline & Hydroquinone monomethylether & & & & \\
\hline & Others & & & & \\
\hline \multicolumn{6}{|l|}{ Luting agents: } \\
\hline \multirow[t]{3}{*}{$\begin{array}{l}\text { Panavia F } 2.0 \\
(\mathrm{PF})\end{array}$} & $\begin{array}{l}\text { Paste A: MDP, Methacrylate monomer, } \\
\text { Filler, Photo initiator, Chemical initiator }\end{array}$ & & $\begin{array}{l}\text { Kuraray Medical Inc. } \\
\text { Tokyo, Japan }\end{array}$ & 20 & $00095 \mathrm{~A}$ \\
\hline & $\begin{array}{l}\text { Brown Paste B: Methacrylate monomer, } \\
\text { Filler, NaF, Photo initiator, Chemical initiator }\end{array}$ & & & & $00087 \mathrm{~A}$ \\
\hline & Oxyguard II: Poly(ethylene glycol), Accelerator & & & & $00491 \mathrm{~A}$ \\
\hline \multirow[t]{2}{*}{$\begin{array}{l}\text { Linkmax MC } \\
(\mathrm{LM})\end{array}$} & $\begin{array}{c}\text { Paste A: Aluminosilicate glass powder, } \\
\text { Methacrylate }\end{array}$ & & $\begin{array}{l}\text { GC Corp. } \\
\text { Tokyo, Japan }\end{array}$ & 20 & 0409271 \\
\hline & $\begin{array}{l}\text { Paste B: Aluminosilicate glass powder, } \\
\text { Methacrylate }\end{array}$ & & & & 0409271 \\
\hline \multirow[t]{2}{*}{$\begin{array}{l}\text { Chemiace II } \\
(\mathrm{CA})\end{array}$} & $\begin{array}{l}\text { Liquid: Multifunctional methacrylate, HEMA } \\
\text { 4-META, BPO }\end{array}$ & & Sun Medical Co. Ltd. & 0 & LG-1 \\
\hline & Powder: Zirconia, Silica, Amine & & & & LM1 \\
\hline \multirow{3}{*}{$\begin{array}{l}\text { Multibond } \\
(\mathrm{MB})\end{array}$} & Liquid: MAC-10, MMA, Amine, & & Tokuyama Dental Corp. & 0 & 325 \\
\hline & Multifunctional methacrylate & & Tokyo, Japan & & \\
\hline & Clear powder: PMMA, BPO & & & & 509 \\
\hline \multirow{3}{*}{$\begin{array}{l}\text { Super-Bond C \& B } \\
\text { (SB) }\end{array}$} & Initiator: $\mathrm{TBB}$ & & Sun Medical Co. Ltd. & 0 & LW62 \\
\hline & Monomer liquid: 4-META, MMA & & & & KE3 \\
\hline & Clear powder: PMMA & & & & KL1 \\
\hline \multirow{4}{*}{$\begin{array}{l}\text { Experimental } \\
(\mathrm{MT})\end{array}$} & Initiator: $\mathrm{TBB}$ & & Sun Medical Co. Ltd. & & LW62 \\
\hline & Monomer liquid: MMA & & Wako Pure Chemical & & TWQ5264 \\
\hline & & & Industries Ltd., Osaka, Japan & & \\
\hline & Clear powder: PMMA & & Sun Medical Co. Ltd. & & KL1 \\
\hline \multirow[t]{2}{*}{$\begin{array}{c}\text { Fuji I } \\
(\mathrm{FI})\end{array}$} & $\begin{array}{l}\text { Powder: Fluo roalumino silicate glass, } \\
\text { Poly (acrylic acid) }\end{array}$ & & GC Corp. & 0 & 0410051 \\
\hline & $\begin{array}{l}\text { Liquid: Poly (acrylic acid), Distilled water, } \\
\text { Carboxylic acid derivative }\end{array}$ & & & & 0401211 \\
\hline
\end{tabular}


GC Corp.).

The organic components of FRC were dissolved in acetone for 60 minutes, and the glass fibers were then air-dried and observed with a color 3D laser microscope (VK-8700, Keyence, Osaka, Japan) at a magnification of $\times 1,000$ (Fig. 1). The FRC contained silanized milled glass fibers (average diameter: 11 $\mu \mathrm{m}$; average length: $150 \mu \mathrm{m}$ ) and colloidal silica. The silane coupling agent used contained 3trimethoxysilylpropyl methacrylate. On the other hand, RC-control contained a reactive prepolymerized filler ${ }^{31)}$ (TMPT filler). The TMPT filler was a composite filler copolymerized with poly (trimethylol propane trimethacrylate). An RC-control sample was burned out at $400^{\circ} \mathrm{C}$ for 30 minutes (Ring Furnace, J. Morita Tokyo MFG. Corp., Saitama, Japan) in order to calculate the ratio of the inorganic components. Weight of the burned-out sample divided by the original weight indicated the percentage of inorganic components.

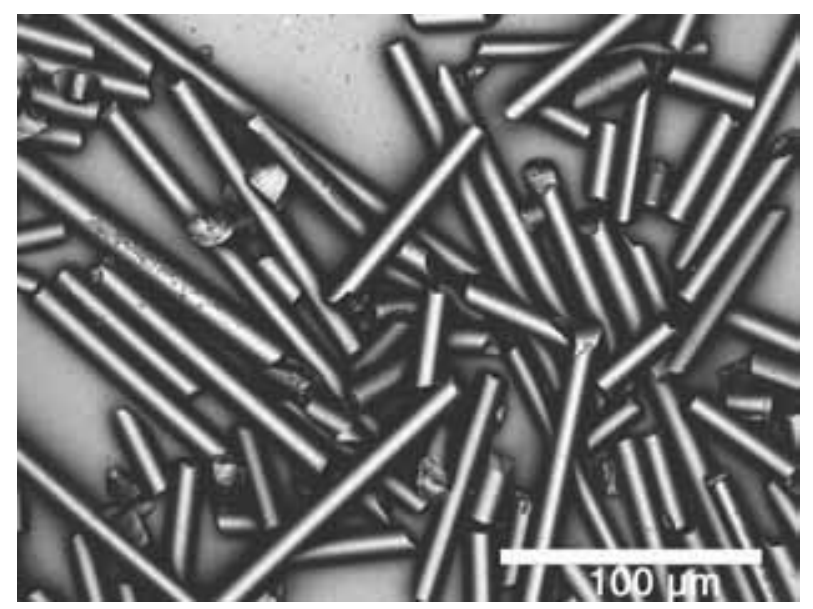

Fig. $13 \mathrm{D}$ laser micrograph of the milled glass fibers contained in the FRC.

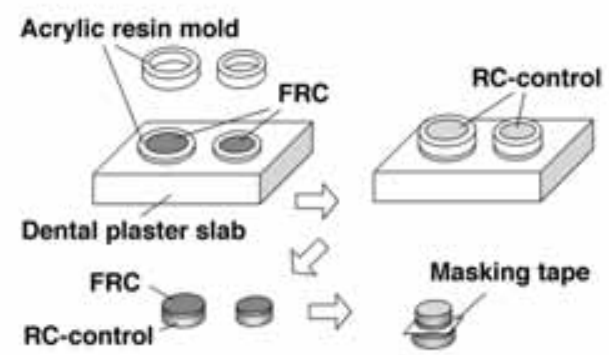

Fig. 2 Schematic illustration of specimen preparation.

\section{Specimen preparation}

An experimental separating agent consisting of $\mathbf{a}$ polyolefin, $n$-heptane, and pigment (Sun Medical Co. Ltd.) was applied to a dental plaster slab (New Fujirock Fast Set, GC Corp.). Two sizes of cylindrical acrylic resin mold (diameter: $8 \mathrm{~mm}$, thickness: 0.5 $\mathrm{mm}$ and diameter: $7 \mathrm{~mm}$, thickness $0.5 \mathrm{~mm}$ ) were placed on the slab and filled with FRC (Fig. 2). The FRC was then polymerized with a photopolymerizing unit (a-Light II, Morita Corp., Tokyo, Japan) for 90 seconds. Additional cylindrical acrylic resin molds (diameter: $8 \mathrm{~mm}$, thickness: $2.5 \mathrm{~mm}$ and diameter: 7 mm, thickness: $2.5 \mathrm{~mm}$ ) were placed concentric on the first molds. The space was filled with RC-control on the FRC paste and then polymerized with the photopolymerizing a-Light II unit for 90 seconds. After removing the cylindrical acrylic resin molds, disk specimens of two sizes were obtained. Disk specimens of RC-control without FRC were fabricated as a control in the same manner.

All disks were air-abraded (Jet Blast III, Morita Corp.) with 50 $\mathrm{\mu m}$ alumina (Hi-Aluminas, Shofu Inc., Kyoto, Japan) for five seconds. An air pressure of $0.2 \mathrm{MPa}$ was applied, and the orifice was positioned approximately $10 \mathrm{~mm}$ from the specimen surface. A piece of $50 \mu \mathrm{m}$-thick masking tape with a circular hole was positioned on the disk specimen to control the bonding area to $5 \mathrm{~mm}$ in diameter. FRC surfaces of the specimens were then bonded with a luting agent in accordance with the manufacturer's directions. As for LM in the present study, no composite primer was used in order to preclude the additional effect of adhesion promoting monomers and to simplify the bonding system.

\section{Shear bond strength test}

At 60 minutes after specimen preparation, a total of 168 bonded specimens were immersed in water at $37^{\circ} \mathrm{C}$ for 24 hours. Half of the specimens were subjected to a thermocycling process $\left(4^{\circ} \mathrm{C}\right.$ and $60^{\circ} \mathrm{C}$ alternately, 60-second dwell time for 20,000 cycles) using a thermocycling apparatus (Rika Kogyo, Tokyo, Japan). Shear testing was carried out at a crosshead speed of $0.5 \mathrm{~mm} /$ minute on a universal testing machine (AGS-10kNG, Shimadzu, Kyoto, Japan). Shearing load was applied parallel to the bonded interface. Six specimens were tested for each condition.

\section{Statistical analysis}

Data were analyzed by three-way analysis of variance (ANOVA) to assess the significance of interaction among three factors - thermocycling, substrate, and luting agent. Mean values for each condition were compared by a post hoc Fisher's Protected LSD test following one-way ANOVA. P-values of 0.05 were regarded as significant. 


\section{Fracture mode}

The debonded surfaces of all specimens were observed through an optical microscope (SMZ-10, Nikon Corp., Tokyo, Japan) at a magnification of $\times 20$. Failure modes were categorized into six groups: adhesive failure at the interface between the luting agent and resin composite $(\mathrm{A})$, cohesive failure within the luting material $(\mathrm{C})$, fracture within the resin composite $(\mathrm{F})$, and three combinations of these modes (AC, CF, and $\mathrm{ACF})$.

\section{RESULTS}

Figure 1 shows the 3D laser micrograph of the fibers contained in the FRC used in the present experiment. The fibers were confirmed to be straight and the lengths were varied.

Table 2 shows the ANOVA results for bond strength. Bond strength was significantly influenced by thermocycling, the substrate, and the luting agent. With the exception of the substrate/luting agent interaction, no significant interactions were found among the factors. The means and standard deviations of shear bond strength before and after thermocycling for 20,000 cycles are listed in Tables 3 and 4 , respectively.
Before thermocycling (Table 3), the mean bond strength evaluated ranged from 3.9 to $28.4 \mathrm{MPa}$. FI showed the lowest bond strength in both FRC and RC-control. The FRC groups bonded with LM, MB, $\mathrm{SB}$, and MT exhibited the highest bond strengths (24.2-28.4 MPa). Although the RC-control groups bonded with $\mathrm{PF}, \mathrm{CA}$, and $\mathrm{MB}$ were not significantly different from each other, LM, SB, and MT showed higher bond strengths than PF. When PF, LM, or $\mathrm{MB}$ was used, the bond strength with FRC was significantly higher than that with RC-control. Most FRC specimens were observed to suffer complete or partial cohesive failure. With the exception of FI, most RC-control specimens suffered complete or partial fracture at the substrate material.

After thermocycling for 20,000 cycles, the bond strength ranged from 0 to $22.1 \mathrm{MPa}$ (Table 4). All samples bonded with FI failed after thermocycling. In the FRC groups, five luting agents (PF, LM, MB, $\mathrm{SB}$, and MT) showed the highest bond strengths, and no statistically significant differences were found among these agents. In the RC-control groups, the bond strengths of three luting agents (MB, SB, and MT) were relatively high compared with the other luting agents (PF, LM, CA, and FI). When PF, LM,

Table 2 Results of analysis of variance for shear bond strength

\begin{tabular}{|c|c|c|c|c|c|}
\hline Source of variation & d.f. & Sum of squares & Mean square & F-value & $\mathrm{P}$-value \\
\hline Ther mocycling & 1 & 954.9 & 954.9 & 59.3 & 0.0001 \\
\hline Substrate & 2 & 1098.0 & 549.0 & 34.1 & 0.0001 \\
\hline Luting agent & 6 & 4681.7 & 780.3 & 48.4 & 0.0001 \\
\hline Ther mocycling/Substrate & 2 & 25.1 & 12.5 & 0.8 & 0.5 \\
\hline Thermocycling/Luting agent & 6 & 110.1 & 18.4 & 1.1 & 0.3 \\
\hline Substrate/Luting agent & 5 & 246.6 & 49.3 & 3.1 & 0.01 \\
\hline Ther mocycling/Substrate/Luting agent & 5 & 66.7 & 13.3 & 0.8 & 0.5 \\
\hline Residual & 140 & 2256.3 & 16.1 & & \\
\hline
\end{tabular}

Table 3 Shear bond strengths and types of bonding failure at 0 thermocycles

\begin{tabular}{|c|c|c|c|c|c|c|c|c|}
\hline \multirow{3}{*}{$\begin{array}{l}\text { Luting agent } \\
\mathrm{PF}\end{array}$} & \multicolumn{4}{|c|}{ FRC } & \multicolumn{4}{|c|}{ RC-control } \\
\hline & \multirow{2}{*}{$\begin{array}{c}\begin{array}{c}\text { Mean }(\mathrm{SD})^{*} \\
(\mathrm{MPa})\end{array} \\
21.8(3.5)^{\text {def }}\end{array}$} & \multicolumn{3}{|c|}{$\begin{array}{l}\text { Bonding failure** } \\
\text { (number of specimens) }\end{array}$} & \multirow{2}{*}{$\begin{array}{c}\begin{array}{c}\text { Mean }(\mathrm{SD})^{*} \\
(\mathrm{MPa})\end{array} \\
13.7(4.5)^{\mathrm{b}}\end{array}$} & \multicolumn{3}{|c|}{$\begin{array}{l}\text { Bonding failure** } \\
\text { (number of specimens) }\end{array}$} \\
\hline & & $\mathrm{AC}(5)$, & $\mathrm{C}(1)$ & & & $\mathrm{AC}(1)$ & $\mathrm{CF}(1)$, & $\mathrm{ACF}(4)$ \\
\hline LM & $24.5(2.7)^{\mathrm{fg}}$ & $\mathrm{AC}(3)$, & $\mathrm{C}(3)$ & & $19.4(6.3)^{\text {cde }}$ & $\mathrm{F}(4)$, & $\mathrm{CF}(2)$ & \\
\hline CA & $19.0(6.5)^{\text {cde }}$ & $\mathrm{AC}(6)$ & & & $17.0(3.1)^{\mathrm{bc}}$ & $\mathrm{CF}(3)$, & $F(1)$, & $\mathrm{ACF}(1)$ \\
\hline $\mathrm{MB}$ & $28.4(4.7)^{\mathrm{g}}$ & $\mathrm{AC}(2)$, & $\mathrm{C}(3)$ & $F(1)$ & $17.9(3.8)^{\mathrm{bcd}}$ & $\mathrm{F}(5)$ & $\mathrm{CF}(1)$ & \\
\hline $\mathrm{SB}$ & $24.2(3.2)^{\mathrm{fg}}$ & $\mathrm{AC}(3)$, & $\mathrm{CF}(1)$ & $\mathrm{ACF}(2)$ & $20.9(4.1)^{\text {cdef }}$ & $\mathrm{CF}(4)$ & $\mathrm{F}(2)$ & \\
\hline $\mathrm{MT}$ & $25.5(3.1)^{\mathrm{fg}}$ & $\mathrm{CF}(3)$, & $\mathrm{F}(3)$ & & $23.1(4.8)^{\mathrm{ef}}$ & $\mathrm{CF}(2)$, & $\mathrm{F}(4)$ & \\
\hline FI & $3.9(0.9)^{\mathrm{a}}$ & $\mathrm{A}(1)$, & $\mathrm{AC}(5)$ & & $7.9(2.9)^{\mathrm{a}}$ & $\mathrm{A}(1)$ & $\mathrm{AC}(5)$ & \\
\hline
\end{tabular}

*Identical letters indicate that the values are not statistically different $(\mathrm{p} \geq 0.05)$.

${ }^{* *} \mathrm{~A}$, adhesive failure at the luting agent-substrate material interface; $\mathrm{C}$, cohesive failure within the luting agent; F, fracture at the substrate material; $\mathrm{AC}, \mathrm{CF}, \mathrm{ACF}$, combined failure involving the above failure modes. 
Table 4 Shear bond strengths and types of bonding failure at 20,000 thermocycles

\begin{tabular}{|c|c|c|c|c|c|c|c|}
\hline \multirow{3}{*}{$\begin{array}{l}\text { Luting agent } \\
\mathrm{PF}\end{array}$} & \multicolumn{3}{|c|}{ FRC } & \multicolumn{4}{|c|}{ RC-control } \\
\hline & $\begin{array}{c}\text { Mean (SD)* } \\
(\mathrm{MPa})\end{array}$ & $\begin{array}{l}\text { Bonding } \\
\text { (number }\end{array}$ & $\begin{array}{l}\text { failure** } \\
\text { of specimens) }\end{array}$ & $\begin{array}{l}\text { Mean (SD)* } \\
(\mathrm{MPa})\end{array}$ & $\begin{array}{l}\text { Bondin } \\
\text { (numbe }\end{array}$ & $\begin{array}{l}\text { failure** } \\
r \text { of specin }\end{array}$ & mens) \\
\hline & $19.7(2.9)^{\operatorname{def}}$ & $\mathrm{AC}(5)$ & $\mathrm{ACF}(1)$ & $9.8(2.3)^{a}$ & $\mathrm{AC}(3)$ & $\mathrm{ACF}(2)$ & $\mathrm{CF}(1)$ \\
\hline LM & $17.8(6.3)^{\text {cdef }}$ & $\mathrm{AC}(5)$ & $\mathrm{ACF}(1)$ & $10.1(3.0)^{\mathrm{ab}}$ & $\mathrm{AC}(5)$ & $\mathrm{ACF}(1)$ & \\
\hline $\mathrm{CA}$ & $14.9(5.7)^{\mathrm{bc}}$ & $A(4)$ & $\mathrm{AC}(2)$ & $13.1(2.6)^{\mathrm{abc}}$ & $\operatorname{ACF}(6)$ & & \\
\hline MB & $22.1(5.4)^{\mathrm{f}}$ & $\mathrm{AC}(3)$, & $\operatorname{ACF}(3)$ & $16.3(2.7)^{\text {cde }}$ & $\mathrm{AC}(2)$ & $\mathrm{CF}(3)$, & $\mathrm{ACF}(1)$ \\
\hline SB & $20.2(3.0)^{\mathrm{ef}}$ & $\mathrm{CF}(5)$ & $\mathrm{F}(1)$ & $17.4(4.8)^{\text {cdef }}$ & $\mathrm{CF}(4)$ & $\mathrm{F}(2)$ & \\
\hline MT & $21.1(2.4)^{\mathrm{ef}}$ & $\mathrm{CF}(6)$ & & $15.0(6.1)^{\mathrm{cd}}$ & $\mathrm{CF}(1)$ & $\mathrm{F}(5)$ & \\
\hline FI & 0 & $\mathrm{~A}(6)$ & & 0 & $\mathrm{~A}(6)$ & & \\
\hline
\end{tabular}

*Identical letters indicate that the values are not statistically different $(\mathrm{p} \geq 0.05)$.

${ }^{* *} \mathrm{~A}$, adhesive failure at the luting agent-substrate material interface; $\mathrm{C}$, cohesive failure within the luting agent; F, fracture at the substrate material; $\mathrm{AC}, \mathrm{CF}, \mathrm{ACF}$, combined failure involving the above failure modes.

$\mathrm{MB}$, and MT were used, the bond strengths with FRC were significantly higher than those with RCcontrol. Furthermore, there were no cases where FRC showed a significantly lower bond strength than RC-control. Most specimens with PF, LM, CA, $\mathrm{MB}$, and FI were observed to suffer complete or partial adhesive failure in both the FRC and RCcontrol groups. In contrast, SB and MT demonstrated no adhesive failures, but rather cohesive failure within the luting agent or in the substrate material.

\section{DISCUSSION}

The present study revealed that this experimental FRC could be successfully bonded with resin-based luting agents. Before thermocycling, FRC showed less substrate fracturing than RC-control despite the higher bond strength (Table 3). It has been reported that FRC is flexible but not tough, as compared to the RC-control material, according to bending tests $\mathrm{s}^{25}$. The flexibility of FRC originates from both the incorporated fiber and the large amount of matrix resin. The majority of monomers used for the FRC matrix posses a soft polyaliphatic carbonate segment. Therefore, a possible explanation was that the FRC dispersed the shear stress at the bonding interface.

With regard to bonding durability, no definitive conclusions should be drawn without clinical evaluation. Thermal stress is one factor that weakens adhesive bonding. On this ground, the thermocycling test is considered as an expedient, in vitro experiment to accelerate aging with controlled thermal stresses in water. Thermal stress is mainly derived from the difference between the thermal expansion coefficients of the substrate materials and the luting agents used, and Young's modulus of the luting agent affects the relief of thermal stress ${ }^{3233}$.
It is known that FRC has a lower Young's modulus $(1.6 \pm 0.2 \mathrm{GPa})$ than RC-control $\left.(4.4 \pm 0.2 \mathrm{GPa})^{25}\right)$. Therefore, thermal stress was better relieved by the FRC layer.

In the present experiment, both FRC and RCcontrol were blasted with alumina. Once the oxygeninhibited unpolymerized layer was removed, strong bonding between the resin-based luting agent and resin composite material was difficult to achieve $^{34}$. FRC contained more methacrylate monomers than RC-control (Table 1). Accordingly, the authors speculated that the residual monomer existing in the FRC specimen contributed to the strong bonding with the resin-based luting agents, in addition to the oxygen-inhibited unpolymerized layer.

The resin-based luting agents evaluated in this study were classified into two categories: compositetype resin cements (PF, LM, and $\mathrm{CA}$ ) and unfilled resins $(\mathrm{MB}, \mathrm{SB}$, and $\mathrm{MT})$. All the unfilled resins contained methyl methacrylate (MMA), which is characterized by a smaller molecular weight than the other monomers used in the composite-type resin cements. Unfilled resins tended to exhibit higher bond strengths than the composite-type resin cements. In particular, in the cases of SB and MT, most specimens failed in substrate or cohesive failure mode. This indicated that the actual adhesive force generated at the bonding interface was superior to the obtained bond strength values.

As shown in Tables 3 and 4, the bond strengths of MT and SB remained at the same level after 20,000 thermocycles. The functional monomer used in SB was 4-methacryloxyethyl trimellitate anhydride (4-META), while MT contained no functional monomers. Apart from 4-META, SB and MT had similar chemical compositions: MMA monomer, poly (methyl methacrylate) powder, and tri- $n$-butylborane initiator for polymerization. These 
results suggested that the effect of 4-META was not critical for resin composite bonding.

Shear bond strengths after 5,000 thermocycles between a composite-type resin cement containing 10methacryloxydecyl dihydrogen phosphate and two commercially available fiber-reinforced resin composites were reported to be $20.1-23.7 \mathrm{MPa}^{28)}$. These values were comparable to those of $\mathrm{PF}$ in the present experiment.

With Fuji I, the glass-ionomer cement, the reduction in bond strength was the greatest. This result agreed with a previous report that a fiber-reinforced resin composite crown cemented with glass ionomer cement debonded after 10,000 thermocycles ${ }^{2}$. Taken together, these results collectively suggested that there were evident differences in the bonding mechanism to resin composites between resin-based luting agents and glass ionomer cements.

In light of the present findings, the hypothesis that luting materials bond to FRC containing milled glass fiber more strongly than to conventional indirect resin composites was confirmed for four luting agents: $\mathrm{PF}, \mathrm{LM}, \mathrm{MB}$, and MT.

In conclusion, the use of FRC improved the bond durability between the indirect composite and resinbased luting agents. Greatest bond strength was achieved when FRC was bonded with PF, LM, MB, $\mathrm{SB}$, and MT, followed by CA. Insufficient bonding was obtained with FI. In constructing indirect composite restorations, the clinician should select a proper luting agent in conjunction with FRC to ensure their long-term durability.

\section{REFERENCES}

1) Behr M, Rosentritt M, Mangelkramer M, Handel G. The influence of different cements on the fracture resistance and marginal adaptation of all-ceramic and fiber-reinforced crowns. Int J Prosthodont 2003; 16: 538-542.

2) Lehmann F, Eickemeyer G, Rammelsberg P. Fracture resistance of metal-free composite crowns - Effects of fiber reinforcement, thermal cycling, and cementation technique. J Prosthet Dent 2004; 92: 258-264.

3) Ehrnford L. Composite laminate veneers with a continuous inorganic phase comprising microporous sintered glass fiber networks. Acta Odontol Scand 1983; 41: 265-270.

4) Gresnigt MM, Özcan M. Fracture strength of direct versus indirect laminates with and without fiber application at the cementation interface. Dent Mater 2007; 23: 927-933.

5) Brunton PA, Cattell P, Burke FJ, Wilson NH. Fracture resistance of teeth restored with onlays of three contemporary tooth-colored resin-bonded restorative materials. J Prosthet Dent 1999; 82: 167 171.

6) Behr M, Rosentritt M, Latzel D, Kreisler T. Comparison of three types of fiber-reinforced composite molar crowns on their fracture resistance and marginal adaptation. J Dent 2001; 29: 187-196.

7) Bohlsen F, Kern M. Clinical outcome of glass-fiberreinforced crowns and fixed partial dentures: a threeyear retrospective study. Quintessence Int 2003; 34: 493-496.

8) Vallittu PK. A review of fiber-reinforced denture base resins. J Prosthodont 1996; 5: 270-276.

9) Marei MK. Reinforcement of denture base resin with glass fillers. J Prosthodont 1999; 8: 18-26.

10) Altieri JV, Burstone CJ, Goldberg AJ, Patel AP. Longitudinal clinical evaluation of fiber-reinforced composite fixed partial dentures: a pilot study. J Prosthet Dent 1994; 71: 16-22.

11) Rosentritt M, Behr M, Leibrock A, Handel G, Friedl $\mathrm{KH}$. Intraoral repair of fiber-reinforced composite fixed partial dentures. J Prosthet Dent 1998; 79: 393398.

12) Rosentritt $\mathrm{M}$, Behr M, Kolbeck $\mathrm{C}$, Handel G. In vitro repair of three-unit fiber-reinforced composite FPDs. Int J Prosthodont 2001; 14: 344-349.

13) Behr M, Rosentritt M, Ledwinsky E, Handel G. Fracture resistance and marginal adaptation of conventionally cemented fiber-reinforced composite three-unit FPDs. Int J Prosthodont 2002; 15: 467-472.

14) Ferrari M, Vichi A, García-Godoy F. Clinical evaluation of fiber-reinforced epoxy resin posts and cast post and cores. Am J Dent 2000; 13: 15B-18B.

15) Kolbeck C, Rosentritt M, Behr M, Lang R, Handel G. In vitro examination of the fracture strength of 3 different fiber-reinforced composite and 1 all-ceramic posterior inlay fixed partial denture systems. J Prosthodont 2002; 11: 248-253.

16) Akkayan B. An in vitro study evaluating the effect of ferrule length on fracture resistance of endodontically treated teeth restored with fiberreinforced and zirconia dowel systems. J Prosthet Dent 2004; 92: 155-162.

17) Salameh Z, Sorrentino R, Papacchini F, Ounsi HF, Tashkandi E, Goracci C, Ferrari M. Fracture resistance and failure patterns of endodontically treated mandibular molars restored using resin composite with or without translucent glass fiber posts. J Endod 2006; 32: 752-755.

18) Torbjörner A, Karlsson S, Syverud M, HenstenPettersen A. Carbon fiber reinforced root canal posts. Mechanical and cytotoxic properties. Eur J Oral Sci 1996; 104: 605-611.

19) Mannocci F, Ferrari M, Watson TF. Intermittent loading of teeth restored using quartz fiber, carbonquartz fiber, and zirconium dioxide ceramic root canal posts. J Adhes Dent 1999; 1: 153-158.

20) Akkayan B, Gülmez T. Resistance to fracture of endodontically treated teeth restored with different post systems. J Prosthet Dent 2002; 87: 431-437.

21) Sirimai S, Riis DN, Morgano SM. An in vitro study of the fracture resistance and the incidence of vertical root fracture of pulpless teeth restored with six postand-core systems. J Prosthet Dent 1999; 81: 262-269.

22) Freilich MA, Duncan JP, Meiers JC, Goldberg AJ. Preimpregnated, fiber-reinforced prostheses. Part I. Basic rationale and complete-coverage and intracoronal fixed partial denture designs. Quintessence Int 1998; 29: 689-696.

23) Lassila LV, Tanner J, Le Bell AM, Narva K, Vallittu PK. Flexural properties of fiber reinforced root canal posts. Dent Mater 2004; 20: 29-36. 
24) Krause WR, Park SH, Straup RA. Mechanical properties of BIS-GMA resin short glass fiber composites. J Biomed Mater Res 1989; 23: 1195-1211.

25) Suzuki S, Saimi Y, Ono T. Evaluation of a new fiber-reinforced resin composite. J Biomed Mater Res B Appl Biomater 2006; 76: 184-189.

26) Estafan DJ, Dussetschleger F. Fabrication of resinbonded three-unit prostheses. Am J Dent 1999; 12: 51-52.

27) Minesaki Y, Suzuki S, Kajihara H, Tanaka T. Effect of reinforcement methods on the retention of resinbonded fixed partial dentures using a composite denture tooth as a pontic: in vitro evaluation. J Adhes Dent 2003; 5: 225-234.

28) Lassila LV, Tezvergil A, Lahdenperä M, Alander P, Shinya A, Shinya A, Vallittu PK. Evaluation of some properties of two fiber-reinforced composite materials. Acta Odontol Scand 2005; 63: 196-204.

29) Bitter K, Priehn K, Martus P, Kielbassa AM. In vitro evaluation of push-out bond strengths of various luting agents to tooth-colored posts. J
Prosthet Dent 2006; 95: 302-310.

30) Bitter K, Meyer-Lüickel H, Priehn K, Martus P, Kielbassa AM. Bond strengths of resin cements to fiber-reinforced composite posts. Am J Dent 2006; 19: 138-142

31) Suzuki S, Nakabayashi N, Masuhara E. The evaluation of new dental resins prepared with polyfunctional methacrylate monomers. J Biomed Mater Res 1982; 16: 275-287.

32) Ikeda Y. Influence of resin cements on durability of metal-resin adhesion. J Jpn Dent Mater 1995; 14: 4251.

33) Imai Y, Ikeda Y. Effect of adding ethylene glycol dimethacrylate to resin cements: durability against thermal stress of adhesion to titanium. Dent Mater J 1997; 16: 74-77.

34) Hisamatsu N, Atsuta M, Matsumura H. Effect of silane primers and unfilled resin bonding agents on repair bond strength of a prosthodontic microfilled composite. J Oral Rehabil 2002; 29: 644-648. 